This PDF is a selection from a published volume from the National Bureau of Economic Research

Volume Title: The Economic Consequences of Demographic Change in East Asia, NBER-EASE Volume 19

Volume Author/Editor: Takatoshi Ito and Andrew Rose, editors

Volume Publisher: University of Chicago Press

Volume ISBN: 0-226-38685-6

ISBN13: 978-0-226-38685-0

Volume URL: http://www.nber.org/books/ito_08-2

Conference Date: June 19-21, 2008

Publication Date: August 2010

Chapter Title: Population Aging and Economic Growth in Asia

Chapter Authors: David E. Bloom, David Canning, Jocelyn E. Finlay

Chapter URL: http://www.nber.org/chapters/c8148

Chapter pages in book: (61 - 89) 


\title{
Population Aging and Economic Growth in Asia
}

\author{
David E. Bloom, David Canning, and Jocelyn E. Finlay
}

\subsection{Introduction}

The demographic transition and evolution of past birth and death rates in Asia have brought about dramatic shifts in the age structure between 1960 and 2005 (Bloom, Canning, and Fink 2008). The combined forces of declining fertility, increasing life expectancy, and the transitional dynamics of varying cohort sizes moving through the age distribution have led to the rapid aging of societies across much of Asia. ${ }^{1}$ From 1960 to 2005, China experienced the largest absolute increase in life expectancy in the world. During the same period, the total fertility rate in the Republic of Korea plummeted from 5.7 to 1.1 - a change that only a handful of countries have experienced. Japan boasts the highest life expectancy in the world at 85.6 for women and 78.7 for men, and it continues to rise.

With a decline in fertility, in the short run the youth-age population share declines and the working-age share increases. Working-age people contribute to the labor force more than youth-age, and if these individuals are gainfully employed (Bloom, Canning, Fink, and Finlay 2007), then while income per worker can remain the same, income per capita increases. In Asia, the decline in the total fertility rate from a regional average of 6.05 (see table 2.1) in 1960, to a regional average of 2.63 has brought with it an

David E. Bloom is Clarence James Gamble Professor of Economics and Demography and chair of the Department of Global Health and Population at the Harvard School of Public Health. David Canning is a Professor of Economics and International Health in the Department of Global Health and Population at the Harvard School of Public Health. Jocelyn E. Finlay is a Research Associate in the Department of Global Health and Population at the Harvard School of Public Health.

1. Aging in Asia has been particularly dramatic, but it is also taking place in nearly all other regions of the world. 


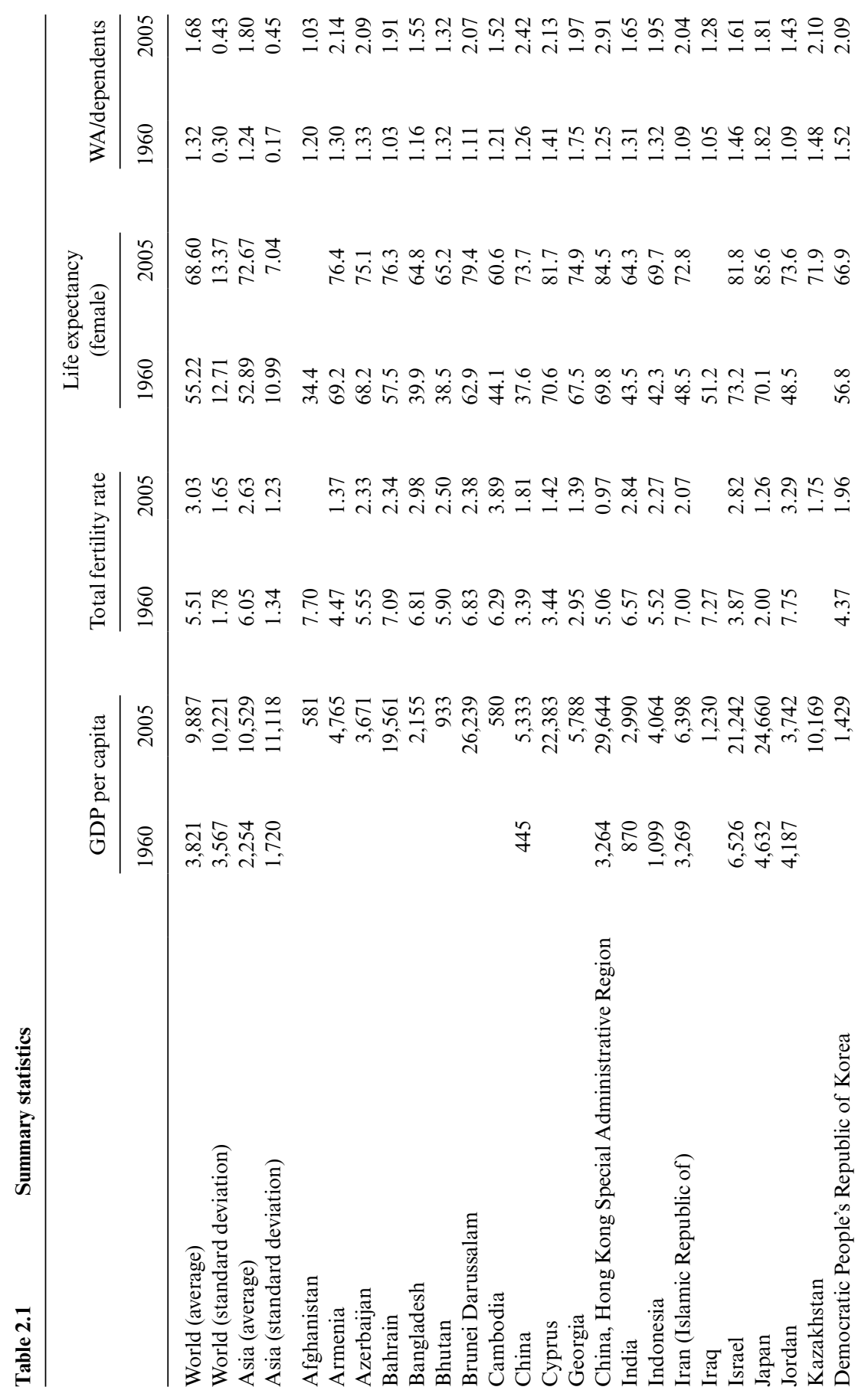




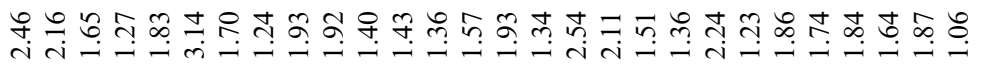

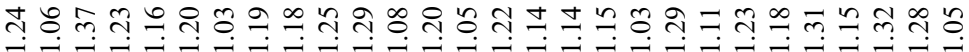

-

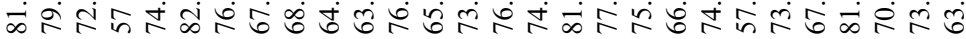

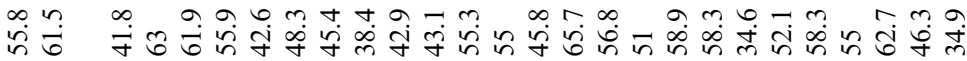

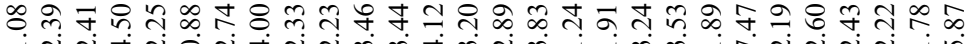

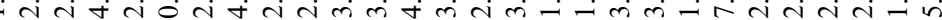

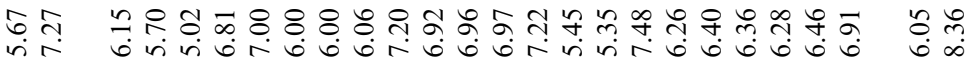

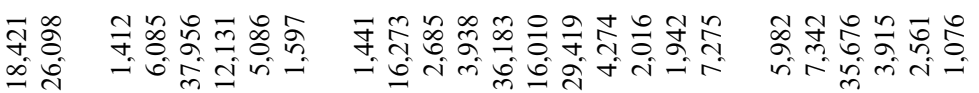

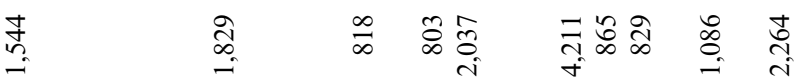

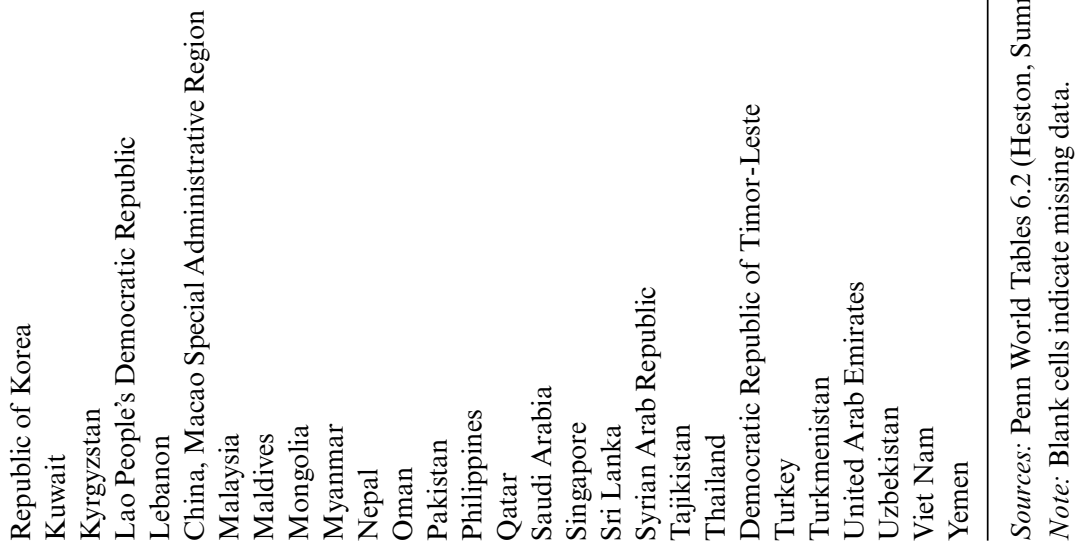


increase in the working-age share. However, as the total fertility rate falls below the replacement rate in many Asian countries, the working-age share will decrease in the long run (Bloom, Canning, Fink, and Finlay 2009b) and old-age shares will increase.

As reviewed in Bloom, Canning, and Fink (2008), a popular view of the negative effects of aging is born of the growth accounting calculation. If labor supply and savings behavior remain unchanged, then labor supply, as well as savings (and thus income) per capita would decline as old-age shares increase and working-age shares decline. However, the dramatic change in family structure creates avenues for behavioral change. With fewer children to care for and the support of elderly parents to care for children and contribute to household expenses, individuals who are of working age may be able to work more than they could previously. Savings patterns may change as life expectancy, income potential, and expenditure requirements change. Furthermore, incentives to invest in one's own and one's children's education may change as life expectancy increases and earning opportunities expand. These behavioral effects may add up to offset the negative accounting effects of aging.

There are three key drivers of population aging: fertility decline, increase in life expectancy, and age-structure dynamics. When we factor in the behavioral responses to the changes in the various demographic variables, we find that these different demographic forces have different effects on economic growth. The decline in fertility causes an increase in the female labor supply (Bloom, Canning, Fink, and Finlay 2009a), an increase in life expectancy will alter savings incentives (Bloom, Canning, and Moore 2007), and a combination of factors leads to increased investment in education per person. The accounting effects of aging, combined with these behavioral responses, mean that aging has an ambiguous effect on economic growth.

Changing institutional settings compound the complexity of analyzing the effects of aging on economic growth. Reforms in social security and diminished adherence to filial piety make for a transformative situation for identifying the responsible agent for elder support and care: adult children, the state, own savings or labor supply, or a company pension.

Will aging have a negative effect on economic growth in Asia? This is the key question that we explore in this chapter. In the next section we break down what we actually mean by aging and illustrate the role of fertility decline and mortality improvements on shifts in age structure. In section 2.3 we use regression analysis to identify the statistical relationship between age structure and economic growth in Asia, and discuss the various behavioral responses to aging in the Asian context. A summary follows.

\subsection{Population Aging in Asia}

We classify a population with an increasing share of old-age persons as one that is aging. This shift in the age structure is brought about by a decline 
in fertility that reduces the number of youth, and thus with no change in the size of the elderly population, the elderly share increases. An increase in this share can also come about by a disproportionate increase in the survival of individuals aged sixty-five and older relative to the improvement in survival rates of other age groups. An increasing share of old-age individuals can also result from past variation in birth and death rates. These three forces all contribute to the trend in most Asian countries of an increasing proportion of individuals aged sixty-five and older (figure 2.6).

The reason for the fertility decline is a contentious issue debated among economists and demographers. Bongaarts $(1984 ; 1994 ; 1999)$ argues that the improvements in contraceptive access have aided the decrease in fertility rates. But Pritchett asserts that access to contraception cannot explain why fertility rates have fallen by so much, so quickly, and that a shift in preferences explains most of the plummet in fertility rates (Pritchett 1994). Deciphering why the total fertility rate has fallen in Asia is not the focus of this chapter; we analyze the economic consequences of the observed decline in the total fertility rate and the associated increase in old-age population shares.

Improvements in life expectancy in many Asian countries between 1960 and 2005 in large part reflect declines in child mortality. Improvements in mortality can be attributed to public health interventions (for example, improvements in nutrition and the provision of water and sanitation) and to medical interventions such as vaccine coverage and the use of antibiotics (Cutler, Deaton, and Lleras-Muney 2006). But health disparities within Asia remain broad: childhood mortality remains high in Laos and Cambodia, for example; life expectancy is the highest in the world in Japan, and survival to sixty is close to certain; and adult mortality is high in West Asian countries relative to East Asia. Despite the disparities, life expectancy has increased in all Asian countries (see table 2.1) between 1960 and 2005.

Aging is also a consequence of the dynamic evolution of past fertility and mortality rates. Cohorts move through the age groups of the population age distribution. The size of the eighty to eighty-five age group in 2000 will depend on births between 1915 and 1920 and the mortality rates this cohort experienced as it aged. When the total fertility rate falls below replacement, the birth cohort will be smaller than the parent cohort (excluding migration effects).

In this section, we examine the effect of fertility and mortality changes between 1960 and 2005 on age structure. This exercise illustrates the dominant role of the fertility decline in shaping the increase in the proportion of old-age individuals. We illustrate how age structure will change between 2005 and 2050 as a consequence of fertility and mortality changes during that period. We also discuss the effects of the dynamic evolution of changes from 1960 to 2005 in mortality and fertility rates on age structure changes between 2005 and 2050 . 


\subsubsection{The Effects of Mortality and Fertility Changes on Age Structure}

In figure 2.1, we illustrate the effect of fertility and mortality changes on age structure between 1960 and 2005. As an example of how to interpret these graphs, consider India and the zero to five age group. The fertility effect of approximately 0.07 indicates that if fertility rates had remained at 1960 rates, then in 2005 the fraction of individuals aged zero to five years old would be seven percentage points higher. The mortality effect of approximately -0.001 indicates that if age-specific mortality rates had remained at 1960 rates then the fraction of individuals in the zero to five age group would be 0.1 percentage points lower than it actually is today. For each of the represented Asian countries (India, Indonesia, Vietnam, China, Japan, Republic of Korea), we see that the fertility changes have had a much greater effect on age structure than the mortality changes. In figure 2.1, we see that the fertility decline in the six example countries has had a similar effect on the respective country's age structure (though the effect in Japan is minimal). If fertility rates had remained at 1960 rates, youth population shares would be higher, working-age shares would be lower, and old-age shares would be lower ${ }^{2}$. Figure 2.1 illustrates the accounting effect of a decline in fertility leading to an increase in the working-age share (or, as the graph represents: if the fertility rate had not fallen from 1960 rates, the working-age share would be lower). As to the mortality effect, we see that in four of the six example countries ${ }^{3}$ if mortality rates had remained at 1960 rates then the youth population share would be lower (as more of the children would have died). With the exception of Vietnam and possibly China, working-age shares would be higher (as improvements in mortality have been concentrated in the childhood age groups).

The cohorts born in the 1960 to 2005 period do not reach the sixty-five and older age group until 2025 to 2070 . Even so, the fertility decline between 1960 and 2005 has an effect on the sixty-five and older age group share. In the case of India in 2005, figure 2.1 illustrates that if the total fertility rate had remained at the 1960 rate then the sixty-five and older age-group population shares would be lower. Changes in the total fertility rate in the present do not affect old-age population sizes in the present, but they do affect old-age population shares in the present.

For the age structure of a population to change (with zero migration), either (a) the fertility rate must change, (b) there must be heterogeneous change in the age-specific mortality rates, or (c) there must have been past variation in mortality and fertility rates.

2. Old-age shares would be lower in all example countries except for the case of Japan, where the fertility decline between 1960 and 2005 has been very small relative to the other example countries.

3. Japan is different as in 1960 child mortality rates were already very low compared to the other example countries. 

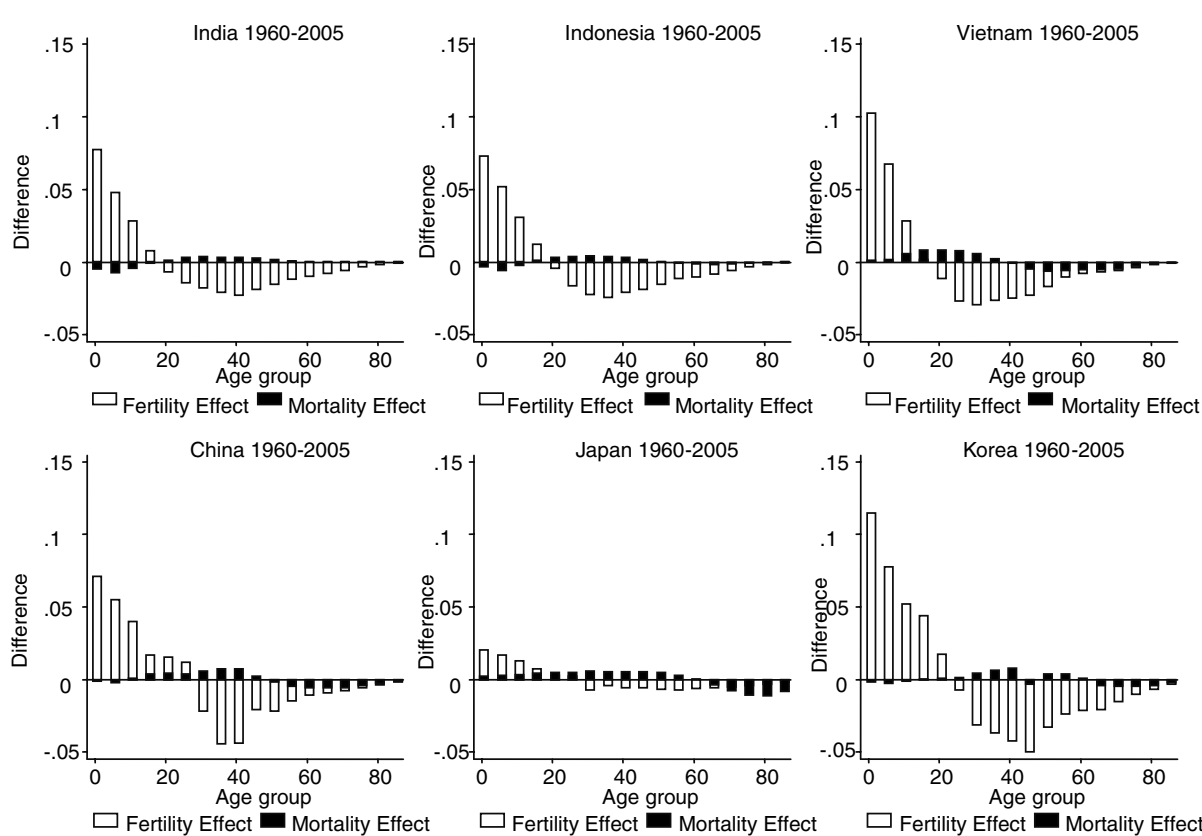

Fig. 2.1 The influence of fertility and mortality change on age structure shifts, 1960-2005

Source: Authors' own calculations using United Nations (2007), World Bank (2007), and ModMatch in Stata 9.

As shown in figure 2.1, the effect of fertility changes on age structure in the selected Asian countries has been much more dramatic than mortality changes (even for China, where female life expectancy climbed from 37.6 to 73.7). As the improvements in life expectancy are a result of improvements in mortality rates across all of the age groups, the proportion of individuals in each age group does not change much even in the face of such steep life expectancy improvements. However, fertility improvements are concentrated in the 0 to 1 age group, which leads to an immediate effect on age structure.

A change in fertility or a heterogeneous change in mortality has a cohort effect that will have an instantaneous effect on age structure. Importantly, this effect will persist through the age distribution as cohorts move through the different age groups. These population dynamics imply that changes in the 1960 to 2005 period will continue to affect the age structure through the 2005 to 2050 period (as discussed in section 2.2.3).

\subsubsection{The Problem of Aging Societies}

The problem with an aging society is that the number of old-age dependents will increase relative to the number of working-age individuals. With- 


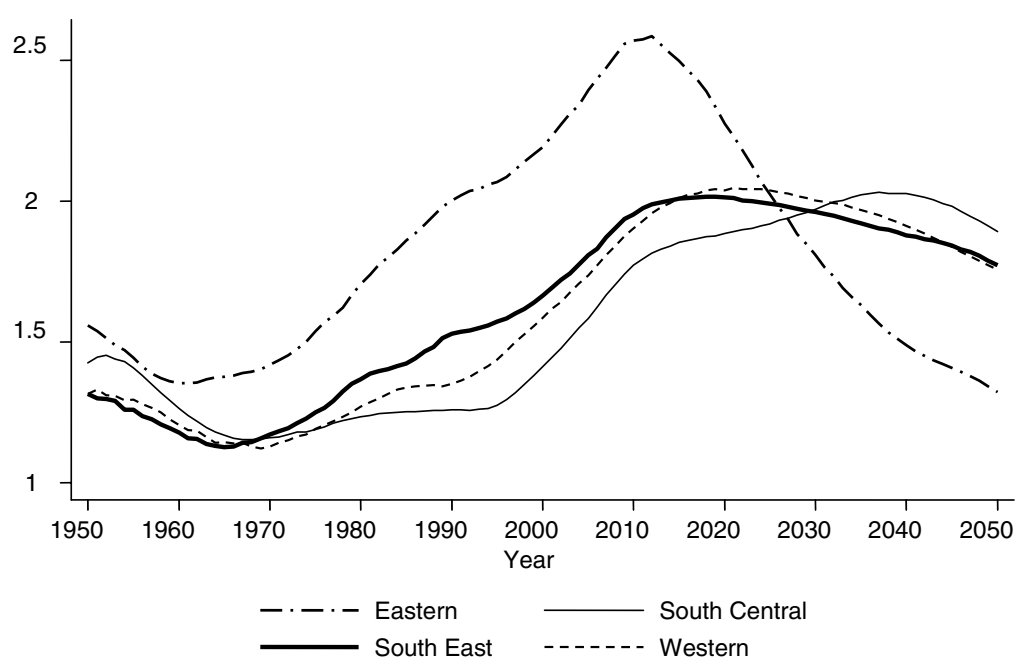

Fig. 2.2 Ratio of working-age population to dependent population, by Asian region Source: United Nations (2007).

out deep analysis, it seems obvious that if people of working age are the workers and people in old age are retired, and that if changes in the age structure of the population bring about no change in behavior (an increase in savings, for example), then there will be a rising number of old-age people dependent on the support of working-age individuals.

We show in figure 2.2 that the working-age to dependents ratio will eventually decline throughout Asia, and comparing figure 2.3 and figure 2.4 we can see that this will be due to the declining ratio of working-age people to old-age dependents. In all Asian regions the ratio of working-age people to old-age dependents will decline (figure 2.4); however, the ratio of workingage to youth-age dependents will increase in all Asian regions except East Asia (figure 2.3). In the past, the rise in the working-age share was backed by a decrease in youth-age shares. In the future, the decline in the working-age share will be backed by an increase in the old-age shares.

The major reason population aging matters is that human productivity and human consumption have different time profiles. Children consume more than they produce. This phase now lasts into the late twenties in many countries as they continue in advanced education. Between twenty-five and roughly sixty-five are the prime working years, in which production exceeds consumption. After age sixty-five, consumption exceeds labor income. In most cases the young are supported by intra-family transfers. Support for the elderly, who have normal consumption and require medical care, is more complex, coming from family support, personal savings, pensions, and social security transfers. The mix of these support systems for the elderly differs greatly across countries. The coping ability of transfer systems (whether 


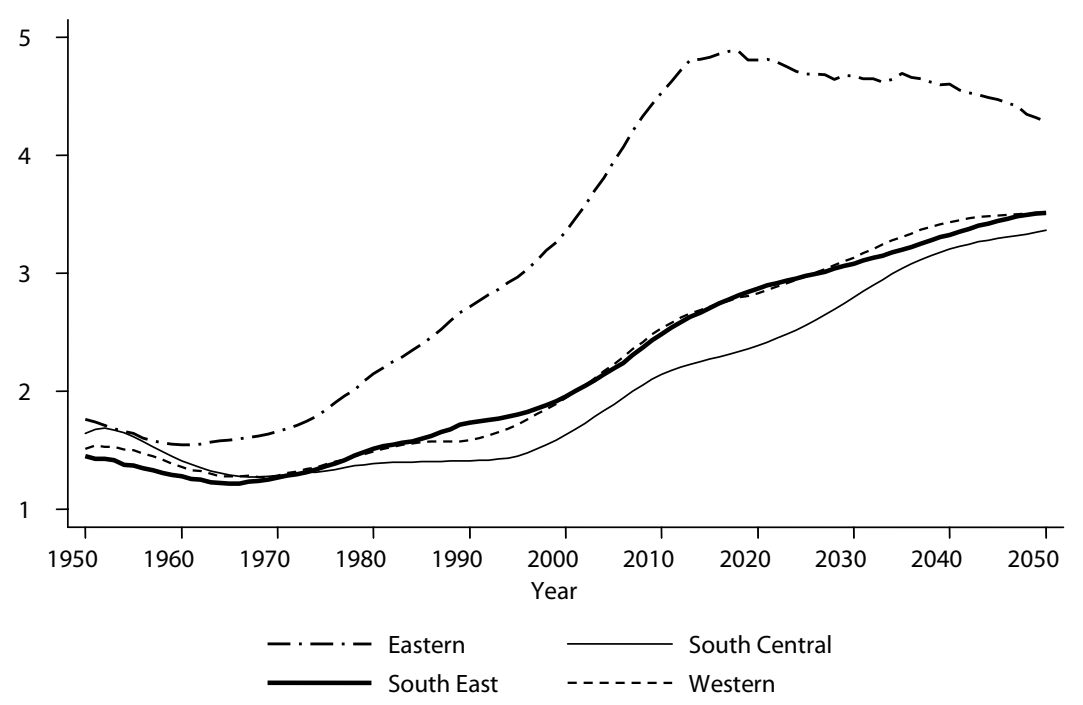

Fig. 2.3 Ratio of working-age population to youth population, by Asian region Source: United Nations (2007).

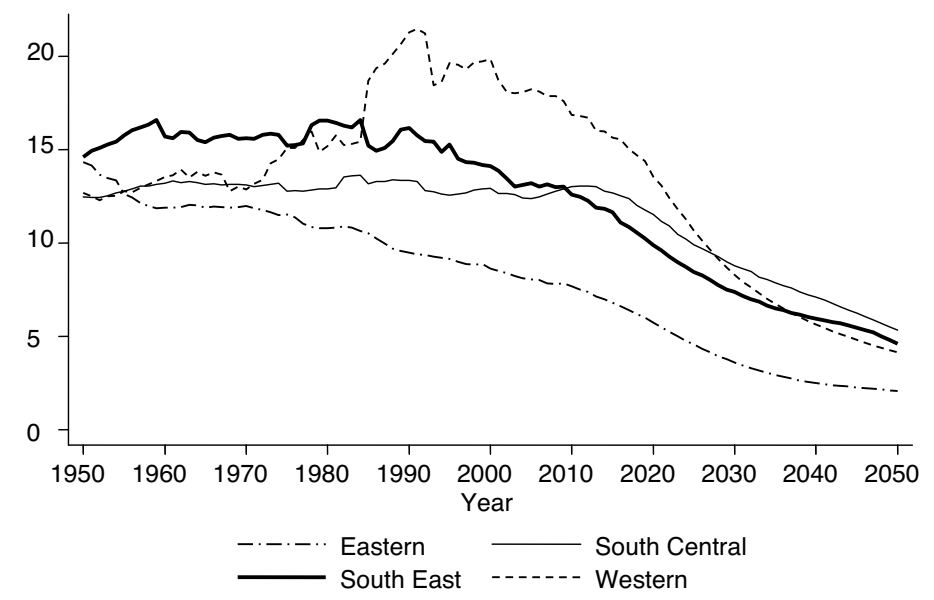

Fig. 2.4 Ratio of working-age population to old-age population, by Asian region Source: United Nations (2007).

mediated by the family or the state) is limited by the rising proportion of the elderly and the consequent high burden on the working-age population.

\subsubsection{Aging in the Future}

In section 2.2.1 we showed that much of the aging of a society is driven by the decline in fertility. Sharp declines in the fertility rate decrease the number of youth and increase the proportion of individuals in old age, even though 

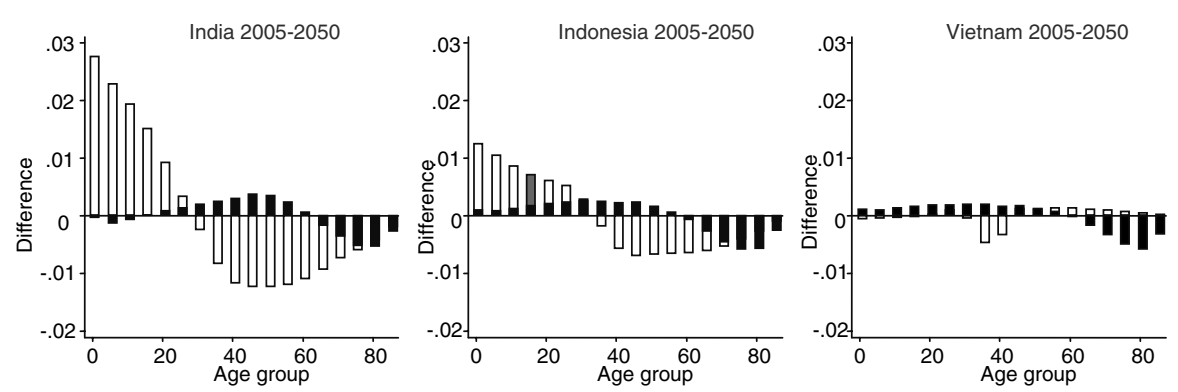

$\square$ Fertility Effect

Mor
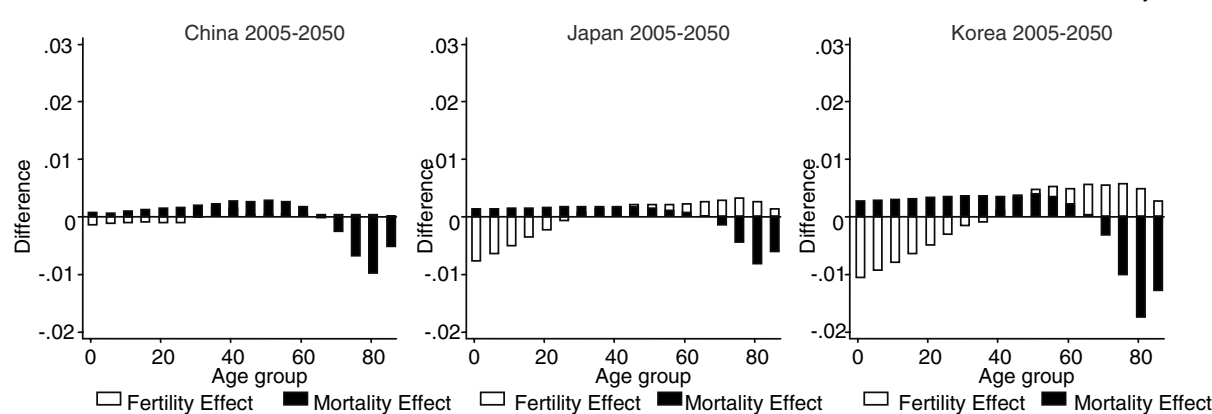

Fig. 2.5 The influence of fertility and mortality change on age structure shifts 2005-2050

the population of old people remains unchanged. Largely as a consequence of the fertility decline, age structure shifted sharply between 1960 and 2005. Changes in the age structure between 2005 and 2050 also appear to be steep in figure 2.6. However, by comparing figure 2.5 with 2005 and 2050 age structure in figure 2.6, we see that changes in age structure between 2005 and 2050 are not fully consequent on changes over that period - in particular the age structure changes for the fifty and older age groups. This is due to the fact that, in addition to the 2005 to 2050 fertility and mortality effects on age structure, shifts in the age structure between 2005 and 2050 will be a result of changes in cohort sizes stemming from steep changes in fertility and mortality rates between 1960 and 2005, as these cohorts move through the age distribution.

As the fertility rate is already below replacement in many Asian countries, and the mortality improvements are diminishing, changes in age structure as a result of changes in fertility and mortality changes over the next forty-five years will not be as dramatic as they were between 1960 and $2005 .{ }^{4}$ With fertility and mortality rates stabilizing at low levels, the changes in the age structure over the next forty-five years will largely reflect dynamic evolu-

4. India is an exception to this. 
tion of past birth and death rates, and the age structure will move toward stability.

To illustrate the dynamic evolution effects of past birth and death rates on the age structure, consider the case of Indonesia in figure 2.5. The graph indicates that if fertility and mortality rates remain at 2005 rates, then by 2050 the share of sixty-five to seventy year olds would be 0.5 percentage points less than what the predicted 2050 sixty-five to seventy year old age share is, as represented in figure 2.6. From figure 2.6, we see that the share of sixty-five to seventy-year-olds increased by 0.035 (3.5 percent); 0.005 of that is explained by fertility and mortality changes between 2005 and 2050, but the remainder $(0.03)$ is explained by past variation in birth and death rates. Thus aging, the increase in the proportion of individuals, aged sixtyfive and older between 2005 and 2050 is largely consequent on fertility and mortality rate changes prior to 2005 .

\subsection{Population Aging and Economic Growth in Asia}

Asia's, and in particular East Asia's, macroeconomic performance is tracked very closely by its demographic transition and resulting changes in age structure. Estimates indicate that as much as one-third of its "economic miracle" can be attributed to a demographic dividend (Bloom and Williamson 1998; Bloom, Canning, and Malaney 2000; Bloom, Canning, and Sevilla 2001; Bloom, Craig, and Malaney 2001; Bloom, Canning, and Sevilla 2003). Another set, due to Kelley and Schmidt (2005) indicates that demographic change accounts for 44 percent of income per capita growth from 1960 to 1990. The first demographic dividend comes about as an accounting effect of a decline in fertility and the resultant rise in the working-age share. When the fertility rate declines, the working-age share increases as the number of individuals of working age increases relative to the number in the youth age groups. With an increase in the working-age share, countries stand to benefit from the proportional increase in the pool of potential workers in the economy, and income per capita can increase. By contrast, the absence of demographic change also accounts for a large portion of Africa's economic debacle (Bloom and Sachs 1998; Bloom, Canning, and Sevilla 2003). In addition, the introduction of demographic factors has reduced the need for the argument that there was something exceptional about East Asia or idiosyncratic to Africa. Most models of economic growth have significant region dummies, usually negative for Sub-Saharan Africa and positive for East Asia, indicating that the poor performance of Africa and the exceptionally good growth performance of East Asia cannot be explained within the models. Once age structure dynamics are introduced into an economic growth model, these regions are much closer to reflecting widely understood drivers of economic growth (Bloom, Canning, and Malaney 2000) and the statistical significance of the region dummy variables disappears. 


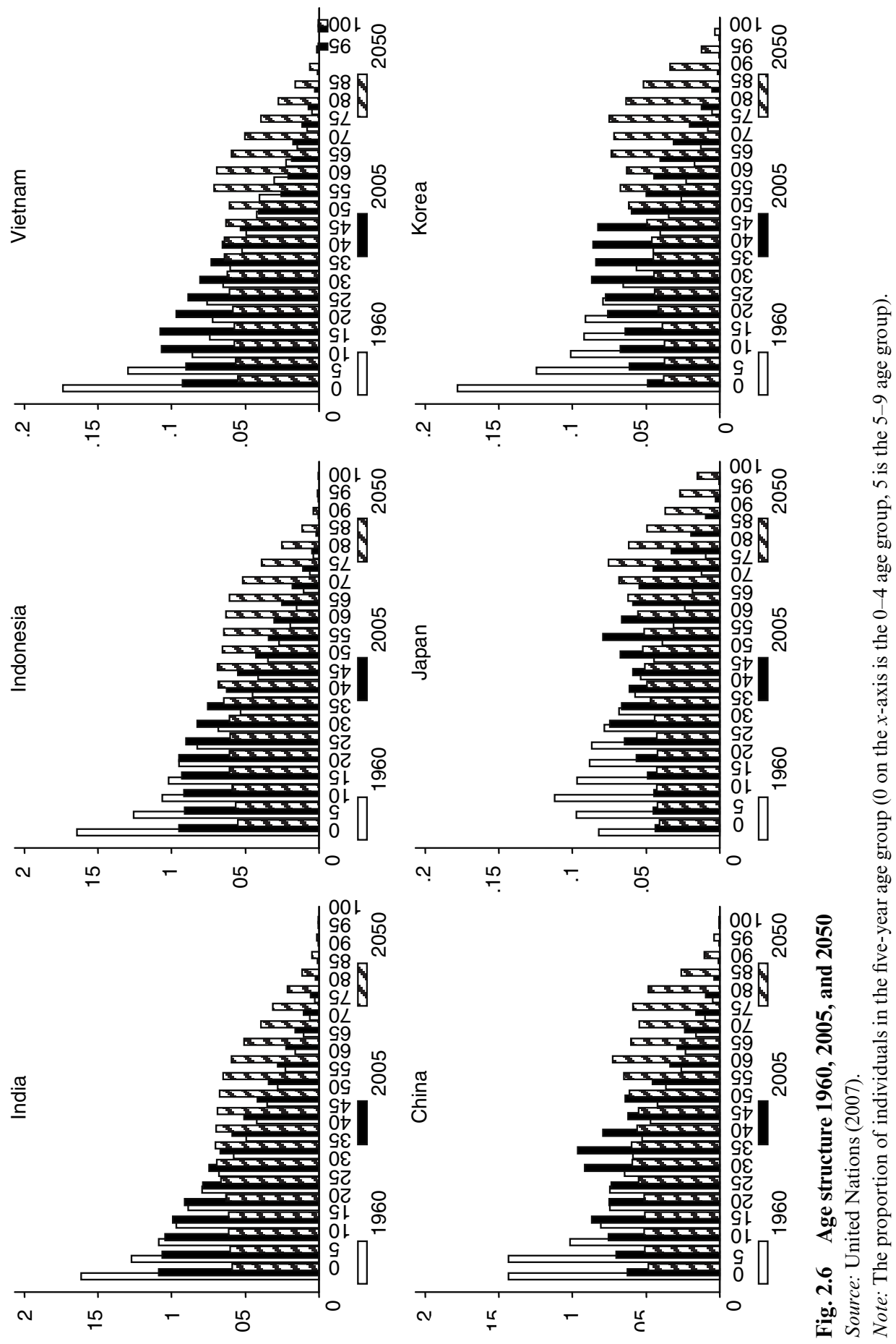


The effect of changes in the working-age share on economic growth is well-documented. We now turn our focus to the effect of old-age share on economic growth. This analysis is not independent of the relationship between working-age share and economic growth. However, when considering the working-age share affecting economic growth, the downward forces of youth- and old-age shares is considered symmetric. In this chapter, we treat youth-and old-age shares separately so as not to impose this symmetry assumption.

\subsubsection{Channels by Which Aging Affects Economic Growth}

In section 2.2 of this chapter we illustrated in detail the process of aging in Asia. Sharp declines in fertility between 1960 and 2005 had dramatic effects on the age structure of the population. Moreover, we showed how the age structure will continue to evolve as population cohorts age between now and 2050.

In this section, we analyze the effect of this shift in age structure on economic growth, with a particular focus on Asia. There are many channels by which the shift in age structure affects economic growth. In the first instance we illustrate the empirical relationship between age-structure shifts and economic growth. Secondly, we discuss the behavioral response to a rapid shift in the age distribution: household-level life-cycle decisions may be influenced by society-level age structure composition. The third channel we examine is the role of institutional settings in the face of rapid changes in age structure. In particular, we look at the role of old-age social security and the incentives created by slow-changing laws.

\subsubsection{Economic Growth and Age Structure}

When analyzing the effects of age structure on economic growth, typically the working-age share is isolated as the age group of interest. In the coming years, however, concern over the potentially depressing effects of old-age dependency on economic growth and the differing effects of youth- and old-age dependency has increased interest in directly observing the partial effect of these latter variables on economic growth.

We take the convergence model framework outlined in Bloom and Canning (2008), and dissect population into youth, $C$, working age, $W A$, and old, $O$.

Growth of gross domestic product (GDP) per worker is characterized by the distance from steady state,

$$
g_{z}=\lambda\left(z^{*}-z_{0}\right)
$$

and a vector of variables, $X$, can affect the steady-state level of labor productivity. Following the discrete time models in Barro and Sala-i-Martin (2004), there is a $\log$-linearization around the steady state. Thus $z=\log (Y / L)$, and the steady-state level of income per worker is summarized as, 


$$
g_{z}=\lambda\left(X \beta-z_{0}\right) .
$$

To then utilize this theory of convergence in an income per capita model, consider the relationship used in Bloom and Canning (2008) that highlights the inclusion of age structure in the form of working-age share,

$$
\frac{Y}{N}=\frac{Y}{L} \frac{L}{W A} \frac{W A}{N} .
$$

If age structure is represented by working-age share, and the participation rate is constant, then,

$$
g_{Y / N}=g_{Y / L}+g_{W A / N}
$$

Growth of income per worker is explained by the convergence term in (2). As for the growth of the working-age share, we wish to observe the separate effects of youth-and old-age dependency on the growth of income per capita and not just the growth of the working-age share. Thus we want to identify,

$$
g_{Y / N}=g_{Y / L}+g_{(N-C-O) / N} .
$$

To isolate the growth of the youth- and old-age we can draw on rules of approximation. Firstly, the difference in logs is an approximation for the growth of the working-age share,

$$
g_{W A / N} \approx \ln \left(\frac{W A}{N}\right)_{t}-\ln \left(\frac{W A}{N}\right)_{0} .
$$

Then, the working-age is the population less the youth-and old-age populations, so growth of the working age can be redefined as

$$
g_{(N-C-O) / N}=\ln \left(\frac{N-C-O}{N}\right)_{t}-\ln \left(\frac{N-C-O}{N}\right)_{0} .
$$

The approximation accuracy of $\ln (1-x) \approx x$ is increasing in the working-age share, and we use this approximation to assert that,

$$
\begin{aligned}
& g_{(N-C-O) / N}=-\left(\frac{C+O}{N}\right)_{t}+\left(\frac{C+O}{N}\right)_{0} \\
& g_{(N-C-O) / N}=\frac{C}{N_{0}}-\frac{C}{N_{t}}+\frac{O}{N_{0}}-\frac{O}{N_{t}} .
\end{aligned}
$$

Using the following substitutions,

$$
y=\log \left(\frac{Y}{N}\right), z=\log \left(\frac{Y}{L}\right), w=\log \left(\frac{W A}{N}\right),
$$

and the fact that taking the logs of both sides of equation (3) gives,

$$
y=z+w .
$$


Then,

$$
\begin{aligned}
& g_{Y I N}=\lambda\left(X \beta-z_{0}\right)+\frac{C}{N_{0}}-\frac{C}{N_{t}}+\frac{O}{N_{0}}-\frac{O}{N_{t}} \\
& g_{Y I N}=\lambda\left(X \beta+w_{0}-y_{0}\right)+\frac{C}{N_{0}}-\frac{C}{N_{t}}+\frac{O}{N_{0}}-\frac{O}{N_{t}} \\
& g_{Y I N}=\lambda\left(X_{0} \beta-\frac{C}{N_{0}}-\frac{O}{N_{0}}-y_{0}\right)-\left[\frac{C}{N_{t}}-\frac{C}{N_{0}}\right]-\left[\frac{O}{N_{t}}-\frac{O}{N_{0}}\right] \\
& g_{Y I N}=\left(X_{0} \beta_{0}+\beta_{1} \frac{C}{N_{0}}+\beta_{2} \frac{O}{N_{0}}+\beta_{3} y_{0}\right)+\beta_{4} \Delta \frac{C}{N_{t}}+\beta_{5} \Delta \frac{O}{N_{t}} .
\end{aligned}
$$

Thus the effects of youth-and old-age dependency on growth of income per capita can be estimated using the specification outlined in equation (11).

An implication of equation (5) is that the coefficients on the change in youth-and old-age shares are minus one. Any deviation from this coefficient is brought about by misspecification. That is, the youth-age and old-age will have heterogeneous effects on income per capita as changes in the youthand old-age shares incite different behavioral responses. High youth-age dependency will cause women to exit the workforce to care for children. Higher old-age shares, in part brought about by higher life expectancies, may reflect lower morbidity thus extending the time which people stay in the workforce. Moreover, the older individuals may accumulate capital (we control for this in our regression analysis) for a longer period before they draw down on savings.

Included in the vector of explanatory variables describing the steady state level of GDP per worker, $X$, are capital stock, education, and institutional quality, and other factors that may affect labor productivity. We also include a global time trend and a random error term in this vector. To measure the growth of income per capita we take the difference in logs. Thus, the estimated equation is,

$$
\begin{aligned}
\ln \left(y_{t}\right)-\ln \left(y_{t-1}\right)= & \beta_{1} y_{t-1}+\beta_{2} e d u_{t-1}+\beta_{3} \operatorname{cap}_{t-1}+\beta_{4} i^{i n s t} t_{t-1} \\
& +\beta_{5} c_{t-1}+\beta_{6} o_{t-1} \beta_{6} \Delta c_{t}+\beta_{6} \Delta o_{t}+\delta_{i}+\delta_{t}+\varepsilon_{i t} .
\end{aligned}
$$

Fixed effects with a lagged dependent variable introduce a Nickell (1981) bias. Thus, we do not estimate a fixed effects model and instead we control for some potential country fixed effects with time invariant country specific geographic variables such as fraction of land in the tropics, and whether the country is landlocked or not. We also control for regional dummies.

It is reasonable to be concerned about possible endogeneity of the age structure variables in the economic growth equation. Periods of high growth may increase the working-age share through migration effects, or have an effect on fertility and thus the youth-age population shares (Bloom and Canning 2008). To control for this issue of reverse causality, we use five-year 
lags of the age structure variables (and an alternative instrument set using five-year-lag fertility and life expectancy).

Using data from the Penn World Tables 6.2 (Heston, Summers, and Aten 2006) for GDP per capita and Penn World Tables 5.6 for capital stock, and demographic data from the World Population Prospects (United Nations 2007), we estimate the effect of changes in age structure on economic growth. In the appendix we detail the data sources with citations.

In table 2.2 we present the descriptive statistics of all of the variables, including the instrumental variables, in the regression analysis. We see from these statistics that a range of countries are represented in the sample: high to low income, low to high fertility rates, low to high infant mortality rates. In table 2.3 we detail the country lists of the country dummies used. The sample of countries is larger than this, and the country lists only detail those of the continent dummies included.

In table 2.4, we present the regression results. In column (1), we present the ordinary least squares (OLS) results for the long run demographic model. In column (2) we introduce the short run effects of youth- and old-age share changes. For these latter variables, a change in the youth-or old-age share will have an impact in the short run on the annual average five year economic growth rate. The initial level of the youth-and old-age shares will affect the long run growth rate. In column (3) we present the two-stage-least-squares results for the demographic model. We use the five year lag of the youth-and old-age change in population share, and the initial year fertility rate and initial year infant mortality rate. In columns (4) and (5) we introduce the Asian and African continent dummies.

Table 2.2

Descriptive statistics

\begin{tabular}{lcccc}
\hline Variable & Mean & $\begin{array}{c}\text { Standard } \\
\text { deviation }\end{array}$ & Min & Max \\
\hline Five-year growth rate of income per capita & 1.35 & 3.36 & -23.48 & 20.38 \\
Log real GDP per capita & 8.44 & 1.15 & 5.14 & 10.49 \\
Capital stock & 0.63 & 1.96 & 0.00 & 22.88 \\
Average years of secondary schooling & 5.45 & 2.83 & 0.35 & 12.05 \\
Trade openness & 65.23 & 46.14 & 3.78 & 462.93 \\
Freedom House Polity Index & 6.14 & 3.30 & 0.19 & 10.00 \\
Life expectancy & 64.06 & 11.84 & 31.20 & 82.10 \\
Tropical location & 0.53 & 0.48 & 0.00 & 1.00 \\
Landlocked & 0.18 & 0.38 & 0.00 & 1.00 \\
Youth-age share & 0.35 & 0.10 & 0.14 & 0.51 \\
Old-age share & 0.06 & 0.05 & 0.01 & 0.20 \\
Youth-age share change & -0.01 & 0.01 & -0.07 & 0.02 \\
Old-age share change & 0.003 & 0.005 & -0.012 & 0.026 \\
Total fertility rate & 3.88 & 1.96 & 1.08 & 8.50 \\
Infant mortality rate & 53 & 46 & 3 & 199 \\
\hline
\end{tabular}

Note: $N=616$ 


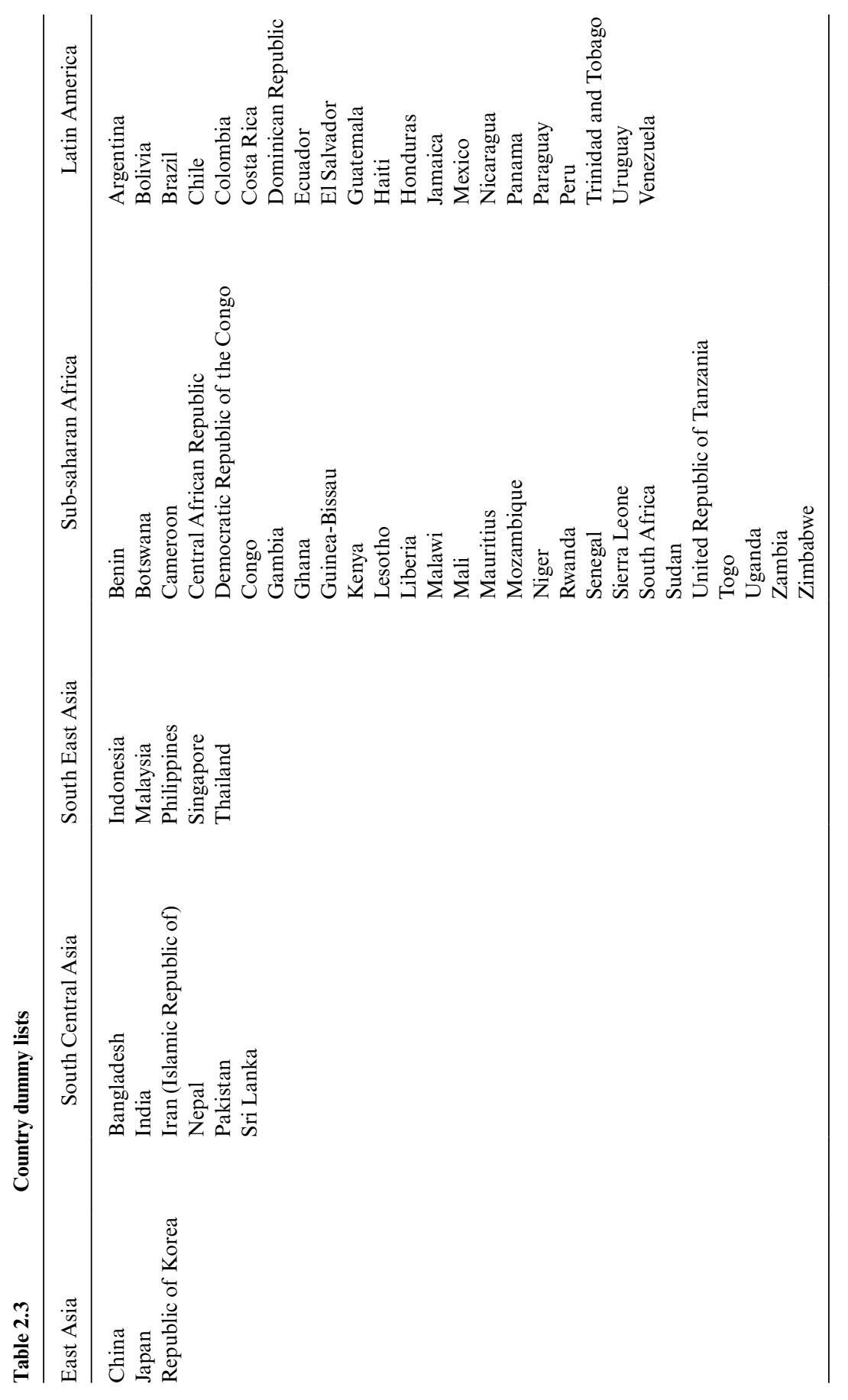




\begin{tabular}{|c|c|c|c|c|c|}
\hline & $\begin{array}{l}\text { OLS } \\
(1)\end{array}$ & $\begin{array}{l}\text { OLS } \\
(2)\end{array}$ & $\begin{array}{l}\text { IV } \\
\text { (3) }\end{array}$ & $\begin{array}{l}\text { OLS } \\
(4)\end{array}$ & $\begin{array}{l}\text { IV } \\
(5)\end{array}$ \\
\hline $\begin{array}{l}\text { Log real GDP per capita in } \\
\text { the base year }\end{array}$ & $\begin{array}{l}-2.184^{* * *} \\
(0.35)\end{array}$ & $\begin{array}{l}-2.077 * * * \\
(0.34)\end{array}$ & $\begin{array}{l}-2.153^{* * *} \\
(0.36)\end{array}$ & $\begin{array}{l}-2.037 * * * \\
(0.39)\end{array}$ & $\begin{array}{l}-2.111^{* * *} \\
(0.41)\end{array}$ \\
\hline $\begin{array}{l}\text { Capital stock in the base } \\
\text { year }\end{array}$ & $\begin{array}{l}0.140^{* * *} \\
(0.041)\end{array}$ & $\begin{array}{l}0.168^{* * *} \\
(0.040)\end{array}$ & $\begin{array}{l}0.171^{* * *} \\
(0.044)\end{array}$ & $\begin{array}{l}0.112^{* *} \\
(0.045)\end{array}$ & $\begin{array}{l}0.120^{* * *} \\
(0.041)\end{array}$ \\
\hline $\begin{array}{l}\text { Average years of secondary } \\
\text { schooling in the base year }\end{array}$ & $\begin{array}{c}-0.0114 \\
(0.080)\end{array}$ & $\begin{array}{l}-0.0577 \\
(0.079)\end{array}$ & $\begin{array}{c}-0.0246 \\
(0.081)\end{array}$ & $\begin{array}{c}-0.0909 \\
(0.078)\end{array}$ & $\begin{array}{c}-0.0641 \\
(0.081)\end{array}$ \\
\hline $\begin{array}{l}\text { Trade openness in the base } \\
\text { year }\end{array}$ & $\begin{array}{l}0.0137^{* * *} \\
(0.0032)\end{array}$ & $\begin{array}{l}0.0143^{* * * *} \\
(0.0030)\end{array}$ & $\begin{array}{l}0.0110^{* * *} \\
(0.0025)\end{array}$ & $\begin{array}{l}0.0149^{* * *} \\
(0.0033)\end{array}$ & $\begin{array}{l}0.0105^{* * *} \\
(0.0027)\end{array}$ \\
\hline $\begin{array}{l}\text { Freedom House Polity } \\
\text { Index in the base year }\end{array}$ & $\begin{array}{l}0.152^{* * *} \\
(0.050)\end{array}$ & $\begin{array}{l}0.140^{* * *} \\
(0.048)\end{array}$ & $\begin{array}{l}0.155^{* * *} \\
(0.051)\end{array}$ & $\begin{array}{l}0.167^{* * *} \\
(0.051)\end{array}$ & $\begin{array}{l}0.187 * * * \\
(0.054)\end{array}$ \\
\hline $\begin{array}{l}\text { Life expectancy in the base } \\
\text { year }\end{array}$ & $\begin{array}{l}0.146^{* * *} \\
(0.027)\end{array}$ & $\begin{array}{l}0.0943 * * * \\
(0.028)\end{array}$ & $\begin{array}{l}0.0748^{* *} \\
(0.032)\end{array}$ & $\begin{array}{l}0.0606^{* *} \\
(0.030)\end{array}$ & $\begin{array}{r}0.0497 \\
(0.034)\end{array}$ \\
\hline $\begin{array}{l}\text { Youth-age share in the base } \\
\text { year }\end{array}$ & $\begin{array}{l}-19.53^{* * *} \\
(3.30)\end{array}$ & $\begin{array}{l}-21.44^{* * * *} \\
(3.57)\end{array}$ & $\begin{array}{l}-24.68^{* * * *} \\
(4.41)\end{array}$ & $\begin{array}{l}-18.37^{* * * *} \\
(3.95)\end{array}$ & $\begin{array}{l}-21.95^{* * * *} \\
(4.62)\end{array}$ \\
\hline $\begin{array}{l}\text { Old-age share in the base } \\
\text { year }\end{array}$ & $\begin{array}{l}-29.46^{* * *} \\
(6.93)\end{array}$ & $\begin{array}{l}-18.38^{* * * *} \\
(6.77)\end{array}$ & $\begin{array}{c}-18.76^{* *} \\
(7.52)\end{array}$ & $\begin{array}{l}-8.902 \\
(7.36)\end{array}$ & $\begin{array}{r}-10.87 \\
(8.19)\end{array}$ \\
\hline Youth-age share change & & $\begin{array}{l}-57.73^{* * * *} \\
(10.5)\end{array}$ & $\begin{array}{l}-75.70 * * * \\
(14.8)\end{array}$ & $\begin{array}{l}-53.57^{* * *} \\
(10.8)\end{array}$ & $\begin{array}{l}-70.38^{* * * *} \\
(14.3)\end{array}$ \\
\hline Old-age share change & & $\begin{array}{l}-57.18^{* *} \\
(23.0)\end{array}$ & $\begin{array}{l}-125.2^{* * * *} \\
(46.6)\end{array}$ & $\begin{array}{l}-64.44^{* *} \\
(25.0)\end{array}$ & $\begin{array}{l}-149.5^{* * *} \\
(48.9)\end{array}$ \\
\hline Tropical location & $\begin{array}{l}-1.103^{* * *} \\
(0.35)\end{array}$ & $\begin{array}{l}-0.928^{* * * *} \\
(0.33)\end{array}$ & $\begin{array}{l}-0.879 * * \\
(0.35)\end{array}$ & $\begin{array}{l}-1.104^{* *} \\
(0.43)\end{array}$ & $\begin{array}{l}-1.135^{* *} \\
(0.44)\end{array}$ \\
\hline Landlocked & $\begin{array}{c}0.389 \\
(0.37)\end{array}$ & $\begin{array}{l}0.506 \\
(0.37)\end{array}$ & $\begin{array}{l}0.692^{*} \\
(0.39)\end{array}$ & $\begin{array}{l}0.606^{*} \\
(0.37)\end{array}$ & $\begin{array}{l}0.754^{*} \\
(0.39)\end{array}$ \\
\hline Latin America Dummy & & & & $\begin{array}{c}0.300 \\
(0.44)\end{array}$ & $\begin{array}{r}0.259 \\
(0.46)\end{array}$ \\
\hline Sub-saharan Africa & & & & $\begin{array}{c}-0.773 \\
(0.56)\end{array}$ & $\begin{array}{l}-0.568 \\
(0.59)\end{array}$ \\
\hline East Asia Dummy & & & & $\begin{array}{l}2.038^{* * *} \\
(0.63)\end{array}$ & $\begin{array}{l}1.895^{* * *} \\
(0.63)\end{array}$ \\
\hline South Central Asia Dummy & & & & $\begin{array}{l}-0.307 \\
(0.59)\end{array}$ & $\begin{array}{l}-0.389 \\
(0.59)\end{array}$ \\
\hline South East Asia Dummy & & & & $\begin{array}{l}1.305^{* *} \\
(0.58)\end{array}$ & $\begin{array}{l}1.554^{* * *} \\
(0.58)\end{array}$ \\
\hline Constant & $\begin{array}{l}20.40^{* * *} \\
(3.15)\end{array}$ & $\begin{array}{l}22.78 * * * \\
(3.24)\end{array}$ & $\begin{array}{l}21.58^{* * *} \\
(3.80)\end{array}$ & $\begin{array}{l}19.14 * * * \\
(4.14)\end{array}$ & $\begin{array}{l}21.80^{* * * *} \\
(4.58)\end{array}$ \\
\hline Year dummies & Yes & Yes & Yes & Yes & Yes \\
\hline Observations & 722 & 720 & 649 & 714 & 643 \\
\hline$R^{2}$ & 0.27 & 0.31 & 0.26 & 0.32 & 0.28 \\
\hline Cragg-Donald $F$-stat & & & 45.70 & & 40.51 \\
\hline Hansen $\mathrm{J} p$-value & & & 0.411 & & 0.500 \\
\hline
\end{tabular}

Notes: Robust standard errors in parentheses. Instruments: five-year lag of the change in the youth- and old-age shares, five-year lag of fertility rates and infant mortality rates.

***Significant at the 1 percent level.

**Significant at the 5 percent level.

*Significant at the 10 percent level. 
We see from the regression results that changes in both youth- and old-age shares over a five-year period have a negative effect on the short run (five year) growth rate. This effect is negative and significant even in the twostage-least-squares specifications in columns (3) and (5). Once we control for the continent dummies, however, the results indicate that the long run effect of the level of old-age population share is negative but not significant. The long run effect of the level of the youth-age population share is, however, negative and significant.

Capital stock, trade openness, and institutional quality each have a positive and significant effect on the five-year growth rate. The significance of these control variables is consistent with other studies: even when controlling for these core variables that explain cross-country differences in economic growth, the level and change in the age structure of the population have an effect on economic growth. Highlighting the importance of demographic change in explaining economic growth is a feature of Bloom, Canning, and Sevilla (2003) but in this chapter, we treat youth-age and old-age population shares as heterogeneous. The positive and significant East Asian dummy indicates that on average, over the 1960 to 2005 period, East Asia's economic growth rate was higher than the global average.

Taking the results in column (5) of table 2.4 , we can interpret the magnitude of the coefficients on the demographic variables. A 10 percentage point decrease in the youth-age share, will increase the economic growth rate by 2.2 percentage points leading to a higher steady state income per capita in the long run. From the results, we see that a change in the old-age share does not have a significant effect on economic performance in the long run. In the short run, if the change in the youth-age share decreases by 1 percent point over a five-year period, then the average annual economic growth rate will increase by 0.7 percentage points. If the change in the old-age share increase by 1.0 percentage point then the average annual economic growth rate in that five year period will decline by 1.5 percentage points. Thus, the increasing old-age shares we observe throughout Asia will have a negative effect on economic growth in the short run, but in the long run it does not appear that the rising old-age shares will impede economic performance. The positive impact of a decline in youth-age shares and the neutrality of the old-age shares on economic growth are consistent with the findings of Kelley and Schmidt (2005).

In past studies, the positive influence of an increase in working-age share may, in part, have been a proxy for the decline in youth-age dependents. The decline in the working-age share that is to come in East Asia over the next forty-five years is coupled with an increase in old-age, and not youth-age, dependency. The observed partial effect of changes in the growth of the working-age share on economic growth may differ in the future, as declines in the working-age share will be coupled with increases in the old-age share, and not increases in the youth-age share. From the regression results in table 
2.4, however, we see that for East Asia, the heterogeneity of the effect of youth-and old-age shares on economic growth is evident in the long run, but not in the short run. In the short run, changes in either youth- and oldage shares have a similar magnitude of effect on economic growth. However, the long run effect differs: in the long run low youth-age shares will have a positive effect on economic growth, but high old-age shares may have an insignificant effect on economic growth.

The results indicate that in the short run both high youth- and old-age dependency will have a negative effect on the growth of income per capita. But in the long run, when the population age distribution stabilizes, higher youth-age dependency will have, for a given working-age share, a negative effect on economic growth, whereas higher old-age dependency will have no effect on economic growth. This difference presumably reflects the inherently greater capacity of economies to adapt to changes in old-age population shares than to changes in youth shares.

Old-age dependency is not a given. The compression of morbidity means that a significant portion of this population can continue to work, if they so desire. By working longer they can save more than in the past for their retirement. But rising income means greater demand for leisure and retirement, and this effect may dominate, leading to early retirement (Costa 1995). However, if retirement is voluntary and older people have saved enough for their old age, they are not dependents. Dependency means financing oldage consumption through transfers. If retirement is funded by productive savings or own labor supply, then the elderly should not be considered dependent. The case of youth dependency is clearer. Born into the world with no financial assets, the young do not have the savings or work-effort potential that the elderly have, and they are clearly dependent.

Our results suggest that high youth-age shares are negatively associated with economic performance in the long run, and high old-age shares may not have a significant effect the long run steady-state level of income per capita. This stands to be potentially good news for those Asian countries that are about to experience a decline in working-age share coupled with an increase in the old-age shares. The increase in income in the past, in part boosted by the increase in the working-age share, was backed by the decline in the youth-age shares. In the future, the decline in working-age share will not necessarily bring with it a decline in income, as this demographic trend will be backed by an increase in old-age population shares and not an increase in youth-age shares.

\subsubsection{Behavioral Change: Labor Supply, Savings, and Education}

Although the model we proposed in the previous section implies age structure variables have coefficients of -1 in the growth equation, the estimation revealed otherwise. This indicates that there is some kind of measurement 
error in age structure effects. This measurement error can be explained by accounting and behavioral responses to age structure shifts.

Given well-established life-cycle variations in behavior, it is reasonable to suppose that changes in age structure will have effects on aggregate outcomes. Changes in age structure bring with them changes in labor supply, savings, and education as the number of people engaging in the various life-cycle decisions changes. For example, since labor supply tends to follow an inverted U-shaped pattern with respect to age, changes in the age composition of the population are likely to have effects on aggregate labor supply. Savings rates also vary with age, with the highest rates occurring for forty- to seventy-year-olds, implying that changes in the age structure will affect aggregate savings rates. Furthermore, increases in life expectancy mean that more people survive through the school ages, and the average number of years of education increases.

However, in addition to these accounting effects there are also behavioral effects of aging. Generational crowding (i.e., being born into a large cohort) may have effects on relative wages and individual labor supply (Easterlin 1980; Bloom, Freeman, and Korenman 1988; Korenman and Neumark 2000). In addition, falling fertility and youth dependency rates may be linked to increased labor market participation, particularly among women, as found in Bloom et al. (2009b).

Improvements in life expectancy (which is a proxy for better health) that are inherent to an aging society can invoke behavioral responses that have a positive effect on economic growth. Better health may improve worker productivity (Bloom, Canning, and Sevilla 2004). However, there may also be a demographic effect as a longer prospective life span can change lifecycle behavior, leading to a longer working life and higher saving for retirement (Bloom, Canning, and Moore 2005; Bloom et al. 2007; Bloom, Canning, and Moore 2007). Moreover, a higher life expectancy may increase the incentive to invest in education, as the years over which returns can be amortized are extended (Finlay 2006).

\section{Labor Supply}

In Bloom et al. (2009b), the authors show that the decline in total fertility rate has had a significant effect on the increase in female labor force participation. They show that a reduction in the fertility rate of one child is associated with an increase in labor force participation of four years. With fewer children, women have more opportunities to stay in, or reenter, the workforce as the time required by child care declines. Increased child care services, and the decline in the stigma of a working mother, have helped to make the option of women staying in (or reentering) the workforce more attractive.

In Bloom et al. (2009b), the Republic of Korea is used as an example to 
illustrate the effect of fertility decline on economic growth. The authors show that in Korea, demographic effects explain about 14 percent of the increase in income per capita. The decline in population growth, the increase in the working-age share, and then the positive female labor force participation response to the decline in the fertility rate all contribute to the rapid rise in income per capita in the Republic of Korea.

The behavioral female labor supply response contributes about 25 percent of the 14 percent increase in income per capita. This is only one of the behavioral responses that can occur during the demographic transition. Further analysis of the savings and education responses may find compounded effects compared with those found in Bloom et al. (2007) and may thus yield even higher estimates of the income effects of demographic change.

\section{Savings}

Central to our understanding of the East Asian "miracle" has been Alwyn Young's work $(1994,1995)$ showing that rapid economic growth in the region was mainly due to increases in factor inputs - notably labor, capital, and education - and not to improvements in total factor productivity. ${ }^{5}$ In order to understand the rise in income levels in East Asia we must therefore understand the driving forces behind the growth in these inputs. All of the Asian "Tiger" economies enjoyed a surge in savings and investment during their period of rapid economic growth. We focus here on Taiwan, for which there are fairly good data on household savings. The private savings rate in Taiwan rose from around 5 percent in the 1950s to well over 20 percent in the 1980s and 1990s. Savings rates vary by age, being highest in Taiwan for households with heads in the fifty- to sixty-year-old range. We would therefore expect changing age structure to be a possible explanation for this increase in aggregate saving. Studies that examine the link between demographic structure and national savings rates do find a strong connection (Leff 1969; Fry and Mason 1982; Mason 1987; Mason 1988; Kelley and Schmidt 1995; Kelley and Schmidt 1996; Higgins and Williamson 1997; Higgins 1998) and suggest that a large part of the savings boom in East Asia can be explained by the changing age structure of the population.

However, Deaton and Paxson (2000) show that, based on household savings data for Taiwan, changes in age structure account for only a modest increase in the overall savings rate, perhaps 4 percentage points. They show that the rise in the aggregate savings rate has not been mainly due to changes in the age composition of the population but, rather, to a secular rise in the savings rates of all age groups.

The question then arises as to why savings rates rose at each age. One possible explanation, proposed by Lee, Mason, and Miller (2000) is that increased savings rates are due to rising life expectancy and a subsequent

5. This argument is controversial, as discussed in Krugman (1994). 
need to fund retirement income. Tsai, Chu, and Chung (2000) show that the timing of the rise in household savings rates matches the increases in life expectancy of the population.

With a fixed retirement age we would expect such a savings effect. However, Deaton and Paxson (2000) argue that in a flexible economy, without mandatory retirement, the main effect of a rise in longevity will be on the span of the working life, with no obvious prediction for the rate of saving. Bloom, Canning, and Moore (2005) formalize this argument to show that under reasonable assumptions the optimal response to an improvement in health and a rise in life expectancy is to increase the length of working life, though less than proportionately, with no need to raise saving rates at all (due to the gains from enjoying compound interest over a longer life span).

The effect of savings on investment and domestic production depends on the nature of the capital market. With perfect capital mobility, demographic change may have an impact on international capital flows (Higgins 1998). In this case, effects on domestic interest rates and investment may be minimal (Poterba 2004). However, if capital markets are imperfect, the demographic transition can lead to a mismatch between the investment needs of a large, young, working-age population and the retirement savings of older workers (Higgins and Williamson 1997).

\section{Education}

Demography can affect educational investments through several mechanisms. Perhaps the most important is the quantity-quality trade-off whereby fertility choices and human capital investment decisions are jointly made. This framework points to lower fertility rates being both a cause and a consequence of increased educational investments, with both fertility and schooling determined by a common set of factors that affect families' incentives.

Notwithstanding families' desired fertility, actual fertility in the absence of contraception may be much higher. The provision of family planning services to populations in which desired fertility is low can both lower fertility outcomes and increase schooling levels. This effect may be particularly pronounced for girls' schooling because with high fertility, girls are frequently kept out of school to help care for their younger siblings. Foster and Roy (1997) show how a randomized trial providing family planning services in Bangladesh affected both fertility outcomes and children's schooling levels.

The quantity-quality trade-off can also appear to some extent at the national level if schooling is publicly funded. Smaller youth cohorts can increase the availability of educational funding per child and can lead to an expansion of public education (Kelley 1996; Lee and Mason 2008).

One reason for an increased incentive to invest in education may be the rise in life expectancy. A longer life increases the time over which education investments can be recouped. Kalemli-Ozcan, Ryder, and Weil (2000) argue 
that the effect of improved health and longevity on educational investments has played a large role in economic growth over the last 150 years. This incentive effect, however, is clearly linked to the prospective working life rather than total lifespan, suggesting that education levels may be linked to planned retirement ages and social security incentives.

\subsubsection{Institutional Settings: Social Security}

With health improvements and longer life expectancies, the optimal response for workers with perfect markets may be to have a longer working life. However, mandatory or conventional retirement ages, coupled with the strong financial incentives to retire that are inherent in many social security systems, seem to result in early retirement and increased needs for saving for old age (Bloom et al. 2007).

Generous state transfer systems not only have financing problems, they undermine and reduce labor supply of the elderly, increasing effective dependency rates. Many social security systems impose a very high effective tax rate on older workers by withholding or reducing benefits if they continue to work.

Singapore, Malaysia, and Hong Kong (China) have fully funded universal systems. These systems consist of personal accounts so an older worker who continues working benefits from a larger sum to retire on. These systems should not discourage work at older ages and should be associated with high savings rates. Taiwan, China, India, Vietnam, and Indonesia do not have universal systems. In these countries planning for retirement has historically been rare. However, they do have systems for the formal sector and public sector that can generate large future liabilities.

Specific social security systems were designed for existing demographic situations and may not be appropriate as the proportion of elderly continues to rise. However, transforming these systems once established is very difficult politically, as entitlements under the systems are difficult to reduce. In countries without universal systems, population aging will put pressure on governments to provide more coverage, given the difficulties experienced by families trying to cope with the issue. The systems put in place will have a large impact on how aging affects those economies.

\subsection{Summary}

In this chapter we have illustrated the effects of aging on economic growth in Asia. Aging is driven by a decline in fertility, an increase in life expectancy, or the dynamic evolution of past variation in birth and death rates. In the first part of the chapter we illustrate these driving forces of aging. We show that between 1960 and 2005 the shift in age structure of the population has been predominantly driven by the rapid decline in fertility, and between 2005 and 2050 the dynamic evolution of fertility and mortality changes in the 
period from 1960 to 2005 will continue to shape the age distribution. In the second part of the chapter, we estimated the statistical relationship between the youth-age, and old-age population shares and economic growth, both in the long run and in the short run. Regression analysis indicates that in the long run, old-age shares may not have a significant impact on economic growth. A change in the old-age shares has a negative effect on economic growth in the short run, but not in the long run. The level of youth-age shares (and the change) has a negative effect on long-run economic performance. This result is good news for Asian countries in the long run as the old-age population share increases.

We discuss that population aging has more than a simple accounting effect on economic growth and we discuss the various behavioral responses that come with the shift in age structure: an increase in female labor force participation as fertility declines, an increase in savings, and an increase in education. These factors act together and may offset any negative accounting effects of a shift in the age structure, thus in the regression analysis we observe an insignificant effect of rising old-age shares on economic performance in the long run. Overall, the effect of aging on economic growth will be ambiguous, as the various behavioral responses may impose economic growth effects of differing magnitudes across different countries. 


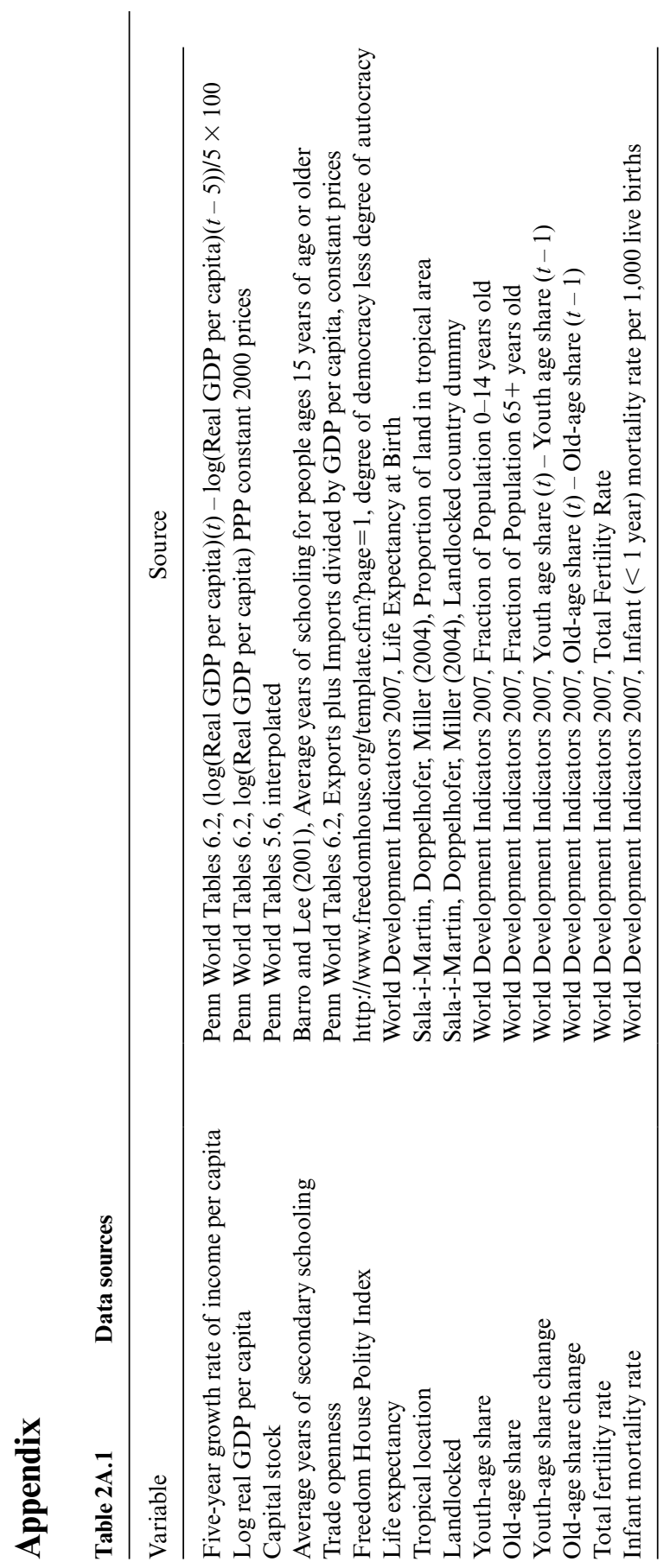




\section{References}

Barro, R. J., and J. W. Lee. 2001. International data on education attainment: Updates and implications. Oxford Economic Papers 53 (3): 541-63.

Barro, R. J., and X. Sala-i-Martin. 2004. Economic growth. Cambridge, MA: MIT Press.

Bloom, D. E., and D. Canning. 2008. Global demographic change: Dimensions and economic significance. Population and Development Review 34 (Supplement): $17-51$.

Bloom, D. E., D. Canning, and G. Fink. 2008. Population aging and economic growth. PGDA working paper no. 31. Boston: Program on the Global Demography of Aging, April.

Bloom, D. E., D. Canning, G. Fink, and J. E. Finlay. 2007. Realizing the demographic dividend: Is Africa any different? PGDA working paper no. 23. Boston: Program on the Global Demography of Aging, May.

. 2009a. Fertility, female labor force participation, and the demographic dividend. Journal of Economic Growth 14: 79-101.

. 2009b. The cost of low fertility in Europe. European Journal of Population, forthcoming.

Bloom, D. E., D. Canning, and P. Malaney. 2000. Population dynamics and economic growth in Asia. Population and Development Review 26 (Supplement): 257-90.

Bloom, D. E., D. Canning, R. K. Mansfield, and M. Moore. 2007. Demographic change, social security systems, and savings. Journal of Monetary Economics 54:92-114.

Bloom, D. E., D. Canning, and M. Moore. 2005. The effect of improvements in health and longevity on optimal retirement and savings. PGDA working paper no. 2. Boston: Program on the Global Demography of Aging, April.

- 2007. A Theory of Retirement. PGDA working paper no. 26. Boston: Program on the Global Demography of Aging, November.

Bloom, D. E., D. Canning, and J. Sevilla. 2001. Economic growth and the demographic transition. NBER Working Paper no. 8685. Cambridge, MA: National Bureau of Economic Research, December.

. 2003. The demographic dividend: A new perspective on the economic consequences of population change. Population Matters Monograph MR-1274. Santa Monica: RAND.

2004. The effect of health on economic growth: A production function approach. World Development 32 (1): 1-13.

Bloom, D. E., P. H. Craig, and P. N. Malaney. 2001. The quality of life in rural Asia. Hong Kong: Oxford University Press.

Bloom, D. E., R. Freeman, and S. Korenman. 1988. The labor market consequences of generational crowding. European Journal of Population 3 (2): 131-76.

Bloom, D. E., and J. Sachs. 1998. Geography, demography, and economic growth in Africa. Brookings Papers on Economic Activity, Issue no. 2: 207-73.

Bloom, D. E., and J. G. Williamson. 1998. Demographic transitions and economic miracles in emerging Asia. World Bank Economic Review 12 (3): 419-55.

Bongaarts, J. 1984. Implications for future fertility trends for contraceptive practice. Population and Development Review 10 (2): 341-52.

. 1994. The impact of population policies: Comment. Population and Development Review 20 (3): 616-20.

. 1999. Fertility decline in the developed world: Where will it end? The 
American Economic Review. Papers and Proceedings of the One Hundred Eleventh Annual Meeting of the American Economic Association 89 (2): 256-60.

Costa, D. 1995. Pensions and retirement: Evidence from Union Army Veterans. Quarterly Journal of Economics 110 (2): 297-320.

Cutler, D., A. Deaton, and A. Lleras-Muney. 2006. The determinants of mortality. Journal of Economic Perspectives 20 (3): 97-120.

Deaton, A., and C. Paxson. 2000. Growth, demographic structure, and national savings in Taiwan. Population and Development Review 26 (Supplement): 141-73.

Easterlin, R. 1980. Birth and fortune: The impact of numbers on personal welfare. New York: Basic Books.

Finlay, J. 2006. Endogenous longevity and economic growth. Harvard University Program on the Global Demography of Aging, Working Paper no. 7.

Foster, A., and N. Roy. 1997. The dynamics of education and fertility: Evidence from a family planning experiment. Philadelphia: The University of Pennsylvania.

Fry, M., and A. Mason. 1982. The variable rate-of-growth effect in the life-cycle saving model. Economic Inquiry 20 (3): 426-42.

Heston, A., R. Summers, and B. Aten. 2006. Penn World Table Version 6.2. Center for International Comparisons of Production, Income and Prices at the University of Pennsylvania, September.

Higgins, M. 1998. Demography, national savings, and international capital flows. International Economic Review 39 (2): 343-69.

Higgins, M., and J. G. Williamson. 1997. Age structure dynamics in Asia and dependence on foreign capital. Population and Development Review 23 (2): 261-93.

Kalemli-Ozcan, S., H. E. Ryder, and D. N. Weil. 2000. Mortality decline, human capital investment, and economic growth. Journal of Development Economics 62 (1): $1-23$.

Kelley, A. C. 1996. The consequences of population growth for human resource development: The case of education. In The impact of population growth on wellbeing in developing countries, eds. D. A. Ahlburg, A. C. Kelley, and K. OppenheimMason, 67-137. Berlin: Springer-Verlag.

Kelley, A. C., and R. M. Schmidt. 1995. Aggregate population and economic growth correlations: The role of the components of demographic change. Demography 32 (4): 543-55.

. 1996. Saving, dependency, and development. Journal of Population Economics 9: 365-86.

. 2005. Evolution of recent economic-demographic modeling: A synthesis. Journal of Population Economics 18: 275-300.

Korenman, S., and D. Neumark. 2000. Cohort crowding and youth labor markets: A cross-national analysis. In Youth employment and joblessness in advanced countries, eds. D. G. Blanchflower and R. B. Freeman, 57-105. Chicago: University of Chicago Press.

Krugman, P. 1994. The myth of Asia's economic miracle. Foreign Affairs 73:62-78.

Lee, R., and A. Mason. 2008. Fertility, human capital, and economic growth over the demographic transition. Paper presented at the 2008 Annual Meetings of the Population Association of America. April 17-19, New Orleans, LA.

Lee, R., A. Mason, and T. Miller. 2000. Life cycle saving and demographic transition: The case of Taiwan. Population and Development Review 26 (Supplement) 194-219.

Leff, N. H. 1969. Dependency rates and savings rates. American Economic Review 59 (5): 886-96.

Mason, A. 1987. National saving rates and population growth: A new model and new evidence. In Consequences of population growth in developing countries, 
eds. G. Johnson and R. D. Lee, 523-60. Madison, WI: University of Wisconsin Press.

1988. Population growth, aggregate saving, and economic development. In World population trends and their impact on economic development, ed. D. Salvatore, 45-58. London: Greenwood Press.

Nickell, S. 1981. Biases in dynamic models with fixed effects. Econometrica 49 (6): 1417-26.

Poterba, J. 2004. The impact of population aging on financial markets. NBER Working Paper no. 10851. Cambridge, MA: National Bureau of Economic Research, October.

Pritchett, L. 1994. Desired fertility and the impact of population policies. Population and Development Review 20 (1): 1-55.

Sala-i-Martin, X., G. Doppelhofer, and R. I. Miller. 2004. Determinants of longterm growth: A Bayesian averaging of classical estimates (BACE) approach. American Economic Review 94 (4): 813-35.

Tsai, I.-J., C. Y. C. Chu, and C.-F. Chung. 2000. Demographic transition and household savings in Taiwan. Population and Development Review 26 (Supplement): 174-93.

United Nations. 2007. World population prospects: The 2006 revision. Comprehensive Dataset (CD-ROM). United Nations, Department of Economic and Social Affairs.

World Bank (2007). World Bank Development Indicators CD-ROM.

Young, A. 1994. Lessons from the East Asian NICs: A contrarian view. European Economic Review 38:964-73.

1995. The tyranny of numbers: Confronting the statistical realities of the East Asian growth experience. Quarterly Journal of Economics 110:641-80.

\section{Comment Roberto S. Mariano}

In light of declining total fertility rate (TFR), increasing life expectancy, dynamically evolving birth and death patterns, and increasing share of oldage population in the age distribution in Asia, this chapter addresses the big question: "What are the economic consequences of population aging?"

The methodology used in the chapter uses both qualitative and quantitative approaches. The qualitative analysis in the chapter is structural and this part of the chapter brings up interesting research issues which I will not get into. Rather, I will focus my comments on the quantitative part of the chapter.

The main message in the chapter is that the economic impact of population aging depends on behavioral responses, in various dimensions, to the shift in the population age distribution. The major factors are:

Roberto S. Mariano is a professor of economics and statistics, and dean of the School of Economics at Singapore Management University, and Professor Emeritus of Economics and Statistics at the University of Pennsylvania. 